\title{
ANALISIS PENERAPAN PPN DAN PPH PASAL 22 ATAS PENGADAAN BARANG PADA KANTOR BADAN PENGAWASAN KEUANGAN DAN PEMBANGUNAN PERWAKILAN SULAWESI UTARA
}

\author{
Arifatul Mufarokhah ${ }^{1}$, Jullie J. Sondakh ${ }^{2}$, Sonny Pangerapan ${ }^{3}$ \\ 1,2,3 Jurusan Akuntansi, Fakultas Ekonomi dan Bisnis, Universitas Sam Ratulangi, Jl. Kampus Bahu, Manado, \\ 95115, Indonesia
}

E-mail : arifatulmufarokhah.am@gmail.com

\begin{abstract}
The treasurer as functional officer has the obligation to deposit and report the tax payable. Examples of taxes that must be deposited and reported by the treasurer are Value Added Tax and Tax Article 22 in the activities of procurement of goods. Procurement of goods for the government is a process of activities to meet or provide the needs and supply of goods for central and local governments. The purpose of this study is to know how to calculate, deposit, and report Value Added Tax and Income Tax Article 22 on Procurement of Goods at Kantor Badan Pengawasan Keuangan dan Pembangunan Perwakilan Sulawesi Utara. This research method using qualitative descriptive method. The result of the research shows that the calculation of Value Added Tax is subject to 10\% tariff and for Tax of Article 22 is charged $1.5 \%$ tariff then deposited using billing code to Bank BNI. Calculation of VAT and Income Tax Article 22 in 2017 at Kantor Badan Pengawasan Keuangan dan Pembangunan Perwakilan Sulawesi Utara is in conformity with the applicable law, but there are still some calculations performed by the treasurer that is not appropriate. In the case of reporting the treasurer does not report, the treasurer should conduct tax reporting in accordance with the rules stipulated by the Minister of Finance and the Directorate General of Taxes in order not to be subject to sanctions on tax administration.
\end{abstract}

Keywords : Calculation, Deposit, Reporting, Value Added Tax, Income Tax Article

\section{PENDAHULUAN}

Di Indonesia pajak merupakan salah satu sumber pemasukan bagi negara yang berguna penting dalam mewujudkan kelangsungan hidup bagi bangsa Indonesia. Dalam melangsungkan pembangunan, negara memerlukan modal yang bersumber dari penerimaan pajak salah satunya, penerimaan pajak sendiri merupakan salah satu dasar sumber penerimaan bagi negara disamping penerimaan bukan pajak seperti migas dan non migas. Pajak adalah sarana bagi pemerintah di dalam menggapai harapan untuk mendapatkan penerimaan baik untuk membayar biaya yang sifatnya langsung atau tidak langsung dari masyarakat untuk pembangunan sosial dan ekonomi. Secara umum pajak dapat dikatakan merupakan keharusan rakyat yang berbentuk loyalitas, yang mana sebagai tugas rakyat, dalam hal pelaksanaan pembagunan bagi keamanan rakyat yang telah diatur pada UU dan kaidah-kaidah.

PPN dan PPh Pasal 22 adalah termasuk dalam jenis-jenis pajak yang ada di Indonesia. PPN adalah pajak tidak langsung yang dibayarkan oleh klien dan diserahkan kepada distributor. Berkaitan mengenai pembayaran akan penyerahan barang dalam aktivitas di bidang impor dan aktivitas di bidang lainnya, adalah pengertian dari PPh Pasal 22 yang mana bendaharawan pemerintah pusat maupun pemerintah Daerah, lembaga pemerintah atau instansi yang bertugas sebagai pemungut. Sesuai dengan Keputusan Menteri Keuangan No. 563/KMK.03/2003, bendaharawan adalah bagian yang melangsungkan pemotongan dan pemungutan retribusi akan biaya yang bersumber dari Anggaran Pendapatan dan Belanja Negara. Dalam tujuan untuk pemotongan dan pemungutan retribusi, bendahara sebagai pihak 
yang telah ditunjuk dan wajib megetahui sudut pandang tentang pemotongan dan pemungutan perpajakan yang berhubungan dengan PPh dan PPN. Pada prinsipnya, dalam melakukan pemenuhan PPh Pasal 22 bendahara harus melakukan pemungutan PPh Pasal 22 kepada rekanan, sebagaimana telah ditentukan.

\section{TINJAUAN PUSTAKA}

Pengertian Akuntansi. Menurut Lubis (2015:4) Akuntansi merupakan pemahaman berupa penerangan yang memberikan penjelasan pada pihak yang memilik wewenang, perihal keadaan dari situasi perusahaan dan kegiatan perdagangan industri. Untuk menerapkan, ilmu akuntansi harus mematuhi dasar-dasar yang berlaku sesuai dengan ketentuan, untuk memudahkan pemilik wewenang dalam membandingkan kinerja industri dengan industri dalam bidang yang sejenis.

Pengerian Akuntansi Perpajakan. Kompetensi saat mengelompokkan, menyimpulkan, mendata juga menerangkan pembicaraan moneter yang dilangsungkan bagi pengusaha serta berniat untuk memutuskan besarnya PKP, yang didapat dalam masa pajak untuk digunakan sebagai aturan penentuan $\mathrm{PPh}$ yang bersangkutan oleh pengusaha selaku WP. akuntansi perpajakan secara lugas dapat didefinisikan sebagai bidang accounting yang menjumlah, menata, menerangkan, bahkan menjabarkan dan membuat rencana perpajakan sehubungan dengan kejadian-kejadian ekonomi (transaksi) perusahaan.

Pajak. Pajak merupakan peran wajib rakyat kepada tanah air yang terutang oleh badan dan individu yang bersifat mengharuskan berdasarkan pada UU serta tidak memperoleh balasan secara langsung dan kemudian berperan untuk memenuhi kebutuhan dan kenyamanan warga negara.

Pajak Pertambahan Nilai. Dikenakan atas penggunaan di tanah air, baik dalam penggunaan JKP ataupun dalam penggunaan BKP. Maka dari pada itu, benda yang bukan di konsumsi di dalam negeri ataupun benda yang dikirim keluar negeri dikenai biaya pajak sebesar $0 \%$ sedangkan benda yang dikirim dari luar negeri dikenai biaya sebesar 10\%, penjelasan diatas merupakan pengertian dari PPN.

DPP Pajak Pertambahan Nilai. Pada Pajak Pertambahan Nilai terdapat beberapa hal yang menjadi tarif dari dasar pengenaan pajaknya. Berikut Dasar pengenaan tarif pajak tersebut : (1) Harga Jual; (2) Pengganti; (3) Nilai Impor; dan (4) Nilai Ekspor.

Perhitungan Pajak Pertambahan Nilai. Perhitungan PPN dijumlah dengan berpedoman pada beban Pajak Pertambahan Nilai dikalikan dengan DPPnya. Untuk melakukan penjumlahan, biaya yang dikenakan sebesar $10 \%$. DPP yang digunakan untuk penyerahan dari BKP adalah besar jumlah harga jualnya. Apabila Jasa Kena Pajak dalam bentuk penyerahan maka dasar pengenaan rentribusiya ialah jumlah alternatifya. untuk kegiatan impor, maka DPPnya adalah nilai impor dan nilai lain yang ditetapkan dalam Keputusan Menteri Keuangan.

Pajak Penghasilan. Pajak Pengahsilan merupakan retribusi langsung yang dikenai pada pembayar retribusi, baik wajib pajak yang kedudukannya selaku pemungut, selaku pemotong, atau selaku pembayar pajak yang terutang tersebut. Besar tarif dan dasar pengenaan serta batas waktu pemungutan, pemotongan, atau pembayaran pajak ditentukan sesuai peraturan perundang-undangan, sehingga dalam perhitungannya wajib pajak harus memperhatikan ketentuan-ketentuan yang terkait tersebut. Undang-undang yang menjabarkan tentang PPh yaitu UU No. 36 Tahun 2008 tentang Pajak Penghasilan.

DPP Pajak Penghasilan. Untuk bisa menjumlahkan $\mathrm{PPh}$, harus terlebih dahulu mencari tahu tentang aturan pembayaran retribusinya. Untuk WP di tanah air dan BUT yang menjadi Dasar Pengenaan Pajaknya ialah PKP. Kemudian bagi penanggung retribusi yang berada di luar tanah air, DPPnya adalah penghasilan bruto.

\section{Pajak Penghasilan}


Pengertian Pajak Penghasilan Pasal 22. PPh Pasal 22 merupakan retribusi yang dipungut oleh bendahara pemerintah (pemerintah pusat atau pemerintah daerah), instansi atau dewan pemerintah. Untuk pembayaran akan penyerahan benda pada badan pemerintah, aktivitas impor, maupun kegiatan di bidang usaha tertentu akan dikenai PPh Pasal 22, yang harus dibayarkan pada tahun berjalan lewat mekanisme pemotongan atau pemungutan pihak-pihak tertentu.

Pajak Penghasilan Pasal 22 Oleh Bendaharawan. Sasaran pemungutan PPh Pasal 22 bendahara adalah penyerahan jasa maupun barang yang dibiayai dari anggaran pusat ataupun anggaran daerah. Penanggung retribusi yang termasuk sebagai wajib pajak dapat berupa badan usaha atau individu pada dasarnya merupakan rekanan pemerintah yang menerima pembayaran untuk penyerahan barang maupun jasa yang dibiayai oleh APBN atau APBD. Bendaharawan sebagai pemungut $\mathrm{PPh}$ Pasal 22 tidak membutuhkan penunjukkan secara khusus karena telah ditetapkan oleh undang-undang. PPh Pasal 22 dipungut berkenaan dengan pemenuhan atas penyerahan barang. Seperti diketahui PPh Pasal 22 yang dipungut oleh bendahara berkenaan karena adanya penyerahan, yang biayanya berasal dari APBN/APBD.

Tarif Pajak Penghasilan Pasal 22. Tarif PPh Pasal 22 oleh Bendahara dikenai sebesar 1,5\% dari tiap melakukan transaksi perdagangan barang dengan nilai di atas Rp1.000.000,00 kepada Instansi Pemerintah. Bagi Perusahaan tidak memiliki NPWP, maka akan dikenai biaya dua kali lipat dan akan dikenakan menjadi sebesar $3 \%$.

\section{Penelitian Terdahulu}

1. Darmayanti (2012)) dengan judul Analisis Perhitungan Pajak Pertambahan Nilai Pada CV. Sarana Teknik Kontrol Surabaya. Hasil Penelitian menampakkan perusahan masih belum serasi dengan perubahan undang-undang perpajakan yang baru, sehingga keuntungan yang diterima lebih sedikit karena tarif pajak terlalu besar.

2. Prasetyo (2017) dengan judul Analisis Perhitungan, Pemungutan, dan Penyetoran PPH Pasal 22 Atas Pengadaan Barang Di PPSDM Migas CEPU. Hasil Penelitian menampakkan Penjumlahan, pengumpulan, dan pemberitahuan PPh Pasal 22 atas pengadaan barang di PPSDM Migas dalam pengerjaannya sudah mengikuti PMK Nomor 107/PMK.010/2015.

\section{METODE PENELITIAN}

Jenis Penelitian. Penelitian ini berbentuk berupa deskriptif, yang di mana dalam penelitian deskriptif ini bertujuan untuk memberikan penjelasan atas sesuatu melalui sebuah penelitian yang akan dilakukan. Penelitian yang akan dilakukan oleh peneliti ini memiliki tujuan untuk mengetahui bagaimana cara perhitungan, penyetoran, dan pelaporan Pajak Pertambahan Nilai dan Pajak Penghasilan Pasal 22, apakah bendahara telah melakukan sesuai dengan undang-undang perpajakan yang berlaku pada Kantor Badan Pengawasan Keuangan dan Pembangunan Perwakilan Sulawesi Utara.

Tempat dan Waktu Penelitian. Tempat penelitian dilakukan pada Kantor Badan Pengawasan Keuangan dan Pembangunan Perwakilan Provinsi Sulawesi Utara, dengan alamat Jalan Diponegoro I/1, Kecamatan Wenang, Mahakeret Timur, Wenang, Kota Manado, Sulawesi Utara, 95112. Waktu pelaksanaan observasi semenjak dari bulan April hingga bulan Juni 2018.

Prosedur Penelitian. Proses identifikasi permasalahan yang ditemukan, menentukan fokus dari masalah, menjalankan penelitian, mengerjakan dan menguraikan data, dan kemudian melaporkan hasil dari penelitian tersebut.

Jenis Data. Dalam melakukan penelitian ini, peneliti mengaplikasikan jenis data berupa bentuk data kualitatif. Peneliti melakukan penelitian mengenai Pajak Pertambahan Nilsai dan Pajak Penghasilan Pasal 22 atas Pengadaan Barang pada Kantor Badan 
Pengawasan Keuangan dan Pembangunan Perwakilan Sulawesi Utara dengan teknik pengumpulan data melalui wawancara dan peninjauan. Selanjutnya peneliti menguraikan data berdasarkan fakta-fakta yang didapatkan, yang memilik tujuan agar dapat memberikan gambaran secara objektif tentang keadaan sebenarnya dari objek yang diteliti.

Sumber Data. Peneliti mengaplikasikan data primer dalam melakukan penelitian ini yang berupa data hasil tanya jawab langsung peneliti dengan bendahara Kantor BPKP Perwakilan Sulawesi Utara dan bukti perhitungan dan penyetoran PPN dan PPh Pasal 22.

Teknik Pengumpulan Data. Pengumpulan data merupakan proses dalam memperoleh data untuk keperluan dalam penelitian. Dalam penelitian ini peneliti menggunakan teknik pengumpulan data adalah :

1. Survei Pendahuluan. Peninjauan dilakukan untuk memahami bagaimana gambaran umum dari Kantor BPKP, menentukan apa yang menjadi rumusan masalah dan identifikasi masalah.

2. Studi Lapangan. Pengumpulan data dengan cara melakukan tanya jawab dengan bendahara, mengumpulkan data dan informasi dari Kantor BPKP tentang bagaimana prosedur perhitungan, penyetoran, dan pelaporan PPN dan PPh Pasal 22.

Teknik Analisis Data. Adapun langkah-langkah yang ditempuh oleh peneliti dalam menguraikan data yang dilakukan dengan tahapan sebagai berikut :

1. Melakukan analisis tentang cara perhitungan PPN dan PPh Pasal 22 berdasarkan UndangUndang Nomor 42 Tahun 2009 dan PMK Nomor 154/PMK.03/2010 dihubungkan dengan susunan aturan perhitungan PPN dan PPh Pasal 22 yang dilakukan oleh Kantor BPKP. Tujuannya untuk mengetahui bagaimana hasil perhitungan yang didapat dari Kantor BPKP.

2. Melakukan analisis tentang cara penyetoran dan pelaporan PPN dan PPh Pasal 22 berdasarkan PMK Nomor 243/PMK.03/2014 dihubungkan dengan susunan pembayaran, dan pemberitahuan PPN dan PPh Pasal 22 yang dilakukan oleh Kantor BPKP, untuk mengetahui apakah penyetoran dan pelaporan yang telah dilakukan oleh Kantor BPKP telah sesuai dengan undang-undang atau peraturan yang berlaku.

\section{HASIL Penelitian DAN PEMBAHASAN}

\subsection{Hasil Penelitian}

Prosedur Perhitungan Pajak Pertambahan Nilai Pada Kantor BPKP Perwakilan Sulawesi Utara. Pajak Masukan pada Kantor BPKP Perwakilan Sulawesi Utara diperoleh dari pembelian barang yang dibutuhkan untuk kepentingan kantor, tarif pajak masukan sama dengan tarif pajak keluaran yaitu sebesar 10\% dari Dasar Pengenaan Pajak, dalam hal ini harga beli Barang Kena Pajak merupakan DPP yang dimaksud. Jumlah Pajak Masukan yang dapat diperhitungkan adalah sebagai berikut: 
Tabel 1. Perhitungan PPN atas Pengadaan Barang Pada Kantor BPKP Perwakilan Sulawesi Tahun 2017

\begin{tabular}{lrrrr}
\hline \multicolumn{1}{c}{ Masa Pajak } & \multicolumn{1}{c}{ Harga Beli } & \multicolumn{1}{c}{ DPP } & Tarif & (dalam rupiah) \\
\hline Januari & 0 & 0 & $10 \%$ & Pajak Terutang \\
Februari & 16.658 .500 & 15.144 .091 & $10 \%$ & 1.514 .500 \\
Maret & 57.400 .600 & 52.182 .363 & $10 \%$ & 5.206 .419 \\
April & 32.940 .075 & 29.945 .522 & $10 \%$ & 2.994 .553 \\
Mei & 16.749 .300 & 15.226 .636 & $10 \%$ & 1.522 .664 \\
Juni & 0 & 0 & $10 \%$ & 0 \\
Juli & 26.661 .000 & 24.237 .273 & $10 \%$ & 2.423 .819 \\
Agustus & 37.533 .500 & 34.121 .363 & $10 \%$ & 3.412 .237 \\
September & 43.434 .357 & 39.485 .776 & $10 \%$ & 3.947 .681 \\
Oktober & 44.484 .020 & 40.440 .017 & $10 \%$ & 4.043 .103 \\
November & 51.073 .625 & 46.430 .565 & $10 \%$ & 4.643 .058 \\
Desember & 57.101 .500 & 51.910 .453 & $10 \%$ & 5.191 .045 \\
\hline Jumlah & 384.036 .477 & 349.124 .059 & & 34.899 .079 \\
\hline
\end{tabular}

Sumber : Kantor BPKP Perwakilan Sulawesi Utara

Prosedur Penyetoran Pajak Pertambahan Nilai Kantor BPKP Perwakilan Sulawesi Utara. Bendahara Kantor BPKP Perwakilan Sulawesi Utara melakukan penyetoran Pajak Pertambahan Nilai melalui e-billing, di mana bendahara BPKP Perwakilan Sulawesi sudah menggunakan aplikasi Surat Setoran Elektronik (SSE) pajak. Setelah bendahara BPKP mengisi formulir SSE, bendahara mendapatkan kode billing yang kemudian di cetak dan digunakan untuk membayar Pajak Pertambahan Nilai ke Bank BNI dan Bank BNI akan meyetorkan langsung ke kas negera, setelah itu bendahara BPKP Perwakilan Sulawesi akan mendapatkan Bukti Penerimaan Negara dari Bank BNI.

Prosedur Perhitungan Pajak Penghasilan Pasal 22 Kantor BPKP Perwakilan Sulawesi Utara. Penyedia yang menjadi rekanan Kantor BPKP Perwakilan Sulawesi merupakan pengusaha yang sudah dikukuhkan menjadi Pengusaha Kena Pajak sehingga tarif PPh Pasal 22 yang dikenakan sebesar 1,5\% dari DPP yaitu, harga beli sebelum pajak. Untuk mengetahui perhitungan $\mathrm{PPh}$ Pasal 22 dapat dilihat pada tabel berikut ini :

Tabel 2. Perhitungan PPh Pasal 22 atas Pengadaan barang pada BPKP Perwakilan Sulawesi Tahun 2017

\begin{tabular}{|c|c|c|c|}
\hline \multirow{2}{*}{ Masa Pajak } & \multirow[b]{2}{*}{ DPP } & \multicolumn{2}{|c|}{ (dalam rupiah) } \\
\hline & & Tarif & Pajak Terutang \\
\hline Januari & 0 & $1,5 \%$ & 0 \\
\hline Februari & 15.144 .091 & $1,5 \%$ & 227.160 \\
\hline Maret & 52.182 .363 & $1,5 \%$ & 757.235 \\
\hline April & 29.945 .522 & $1,5 \%$ & 449.183 \\
\hline Mei & 15.226 .636 & $1,5 \%$ & 228.496 \\
\hline Juni & 0 & $1,5 \%$ & 0 \\
\hline Juli & 24.237 .273 & $1,5 \%$ & 362.809 \\
\hline Agustus & 34.121 .363 & $1,5 \%$ & 511.822 \\
\hline September & 39.485 .776 & $1,5 \%$ & 592.309 \\
\hline Oktober & 40.440 .017 & $1,5 \%$ & 606.652 \\
\hline November & 46.430 .565 & $1,5 \%$ & 696.459 \\
\hline Desember & 51.910 .453 & $1,5 \%$ & 778.657 \\
\hline Jumlah & 349.124 .059 & & 5.210 .782 \\
\hline
\end{tabular}

Sumber : Kantor BPKP Perwakilan Sulawesi Utara 
Prosedur Penyetoran Pajak Penghasilan Pasal 22 Kantor BPKP Perwakilan Sulawesi Utara. Bendahara BPKP Perwakilan Sulawesi Utara memliki kewajiban melakukan pemungutan pada saat pelaksanaan pembayaran atas penyerahan barang oleh rekanan, serta penyetoran PPh Pasal 22 ke kas negara. Bendahara BPKP melakukan penyetoran PPh Pasal 22 melalui e-billing dengan menggunakan NPWP rekanan, setelah mengisi semua data bendahara BPKP akan mendapatkan kode billing, kemudian kode billing tersebut digunakan bendahara BPKP untuk membayar PPh Pasal 22 ke Bank BNI dan Bank BNI akan menyetorkan PPh Pasal 22 ke kas negara, setelah melakukan pembayaran bendahara akan mendapatkan Bukti Penerimaan Negara.

\subsection{Hasil Pembahasan}

Analisis Perhitungan Pajak Pertambahan Nilai Pada Kantor BPKP Perwakilan Sulawesi Utara. Berdasarkan perbadingan data yang di dapat dari Kantor Badan Pengawasan Keuangan dan Pembangunan Perwakilan Sulawesi Utara dan perhitungan yang dilakukan oleh peneliti sesuai dengan peraturan undang-undang Pajak Pertambahan Nilai menunjukan selisih yang terjadi pada perhitungan di atas, di karenakan adanya pembulatan dan kurang bayar dari pihak Kantor BPKP Perwakilan Sulawesi Utara sebesar Rp. 13.899. berikut tabel perbandingan data tersebut:

Tabel 3. Analisis Perhitungan Pajak Pertambahan Nilai atas Pengadaan Barang Pada Kantor BPKP Perwakilan Sulawesi Tahun 2017

\begin{tabular}{lrrr}
\hline Masa Pajak & \multicolumn{1}{c}{$\begin{array}{c}\text { Perhitungan } \\
\text { menurut } \\
\text { Undang-Undang PPN }\end{array}$} & $\begin{array}{c}\text { Perhitungan yang dilakukan oleh } \\
\text { Kantor BPKP }\end{array}$ & $\begin{array}{c}\text { Perbandingan dari } \\
\text { Kedua Perhitungan }\end{array}$ \\
\hline Januari & 0 & 0 & 0 \\
Februari & 1.514 .409 & 1.514 .500 & 91 \\
Maret & 5.218 .236 & 5.206 .419 & 11.817 \\
April & 2.994 .552 & 2.994 .553 & 1 \\
Mei & 1.522 .663 & 1.522 .664 & 1 \\
Juni & 0 & 0 & 0 \\
Juli & 2.423 .727 & 2.423 .819 & 92 \\
Agustus & 3.412 .136 & 3.412 .237 & 101 \\
September & 3.948 .577 & 3.947 .681 & 896 \\
Oktober & 4.044 .001 & 4.043 .103 & 898 \\
November & 4.643 .056 & 4.643 .058 & 2 \\
Desember & 5.191 .045 & 5.191 .045 & 0 \\
\hline Jumlah & 34.912 .402 & 34.899 .079 & 13.899 \\
\hline Sumber & & &
\end{tabular}

Sumber : Data sekunder yang diolah

Analisis Prosedur Penyetoran Pajak Pertambahan Nilai Pada Kantor BPKP Perwakilan Sulawesi Utara. Bendahara BPKP Perwakilan Sulawesi Utara melakukan pemungutan dan penyetoran Pajak Pertambahan Nialai melalui e-billing di mana terhitung mulai 1 Januari 2016, sesuai dengan Surat Edaran Direktorat Jenderal Pajak Nomor SE11/PJ/2016, semua Bank Persepsi (bank yang meneriman pembayaran pajak) harus melaksanakan pembayaran pajak secara elektronik seperti penerapan MPN G2 dan tidak akan melayani pembayaran manual lagi. Jadi dalam melakukan penyetoran bendahara BPKP harus membuat ID billing, kemudian bendahara mengisi formulir Surat Setoran Elektronik, setelah bendahara mengisi formulir dengan lengkap bendahara akan mendapat kode billing yang kemudian harus di cetak dan digunakan untuk membayar Pajak Pertambahan Nilai ke Bank 
BNI, setelah itu Bank BNI akan menyetorkan langsung ke kas negara, Bank BNI akan memberikan bukti pembayaran yaitu Bukti Penerimaan Negara.

Analisis Prosedur Pelaporan Pajak Pertambahan Nilai Pada Kantor BPKP Perwakilan Sulawesi Utara. Dalam pelaporan Pajak Pertambahan Nilai bendahara BPKP Perwakilan Sulawesi Utara tidak melakukan pelaporan karena bendahara menganggap bahwa pembayaran Pajak Pertambahan Nilai kepada Direktorat Jenderal Pajak melalui aplikasi $e$ billing, bendahara sudah menganggap pihak Direktorat Jenderal Pajak sudah mengetahui tentang pembayaran tersebut sehingga tidak diperlukan lagi pelaporan Pajak Pertambahan Nilai, sedangkan menurut Peraturan Menteri Keuangan Nomor 243/PMK.03/2014 "pemungut PPN wajib melaporkan PPN atau PPnBM yang telah dipotong, ke Kantor Pelayanan Pajak tempat pemungut PPN terdaftar paling lama akhir bulan berikutnya setelah Masa Pajak berakhir" artinya sesudah melakukan pembayaran melalui e-billing bendahara seharusnya tetap melakukan pelaporan Pajak Pertambahan Nilai yang menyatakan bahwa BPKP telah melakukan pembayaran Pajak Pertambahan Nilai melalui DJP online.

Analisis Perhitungan Pajak Penghasilan Pasal 22 Pada Kantor BPKP Perwakilan Sulawesi Utara. Berdasarkan perbadingan data yang di dapat dari Kantor Badan Pengawasan Keuangan dan Pembangunan Perwakilan Sulawesi Utara dan perhitungan yang dilakukan oleh peneliti sesuai peraturan undang-undang Pajak Penghasilan Pasal 22 menunjukan selisih yang terjadi pada perhitungan di atas, di karenakan adanya pembulatan dan kurang bayar dari pihak Kantor BPKP Perwakilan Sulawesi Utara sebesar Rp. 26.248. berikut tabel perbandingan data tersebut:

Tabel 4. Analisis Perhitungan PPh Pasal 22 atas Pengadaan barang Pada Kantor BPKP Perwakilan Sulawesi Tahun 2017

(dalam rupiah)

\begin{tabular}{lrrr}
\hline Masa Pajak & $\begin{array}{c}\text { Perhitungan menurut } \\
\text { Undang-Undang PPh } \\
\text { Pasal 22 }\end{array}$ & $\begin{array}{c}\text { Perhitungan yang dilakukan oleh } \\
\text { Kantor BPKP }\end{array}$ & $\begin{array}{c}\text { Perbandingan dari } \\
\text { Kedua Perhitungan }\end{array}$ \\
\hline Januari & 0 & 0 & 0 \\
Februari & 227.161 & 227.160 & 1 \\
Maret & 782.735 & 757.235 & 25.500 \\
April & 449.182 & 449.183 & 1 \\
Mei & 228.399 & 228.496 & 97 \\
Juni & 0 & 0 & 0 \\
Juli & 363.559 & 362.809 & 750 \\
Agustus & 511.820 & 511.822 & 2 \\
September & 592.286 & 592.309 & 23 \\
Oktober & 606.600 & 606.652 & 52 \\
November & 696.458 & 696.459 & 1 \\
Desember & 778.656 & 778.657 & 1 \\
\hline Jumlah & 5.236 .856 & 5.210 .782 & 26.248 \\
\hline Sumber & & &
\end{tabular}

Sumber : Data sekunder yang diolah

Analisis Penyetoran Pajak Penghasilan Pasal 22 Pada Kantor BPKP Perwakilan Sulawesi Utara. Untuk penyetoran Pajak Penghasilan Pasal 22 Bendahara Kantor Badan Pengawasan Keuangan dan Pembangunan Perwakilan Sulawesi Utara melakukan penyetoran melalui e-billing, di mana e-billing pajak adalah sistem bayar pajak online dengan cara pembuatan kode billing atau ID billing terlebih dahulu. Jadi bendahara BPKP mengisi formulir untuk pembayaran PPh Pasal 22, setelah bendahara BPKP mengisi data dengan lengkap, bendahara tinggal mencetak kode billing untuk digunakan dalam membayar $\mathrm{PPh}$ 
Pasal 22 ke Bank BNI, dari Bank BNI bendahara BPKP akan mendapatkan bukti yaitu Bukti Penerimaan Negara.

Analisis Pelaporan Pajak Penghasilan Pasal 22 Pada Kantor BPKP Perwakilan Sulawesi Utara. Bendahara Kantor Badan Pengawasan Keuangan dan Pembangunan Perwakilan Sulawesi Utara tidak melakukan pelaporan Pajak Penghasilan Pasal 22 karena bendahara menganggap bahwa setelah melakukan pembayaran atas PPh Pasal 22 kepada Direktorat Jenderal Pajak melalui aplikasi e-billing, bagi bendahara BPKP sudah cukup, jadi bendahara BPKP berfikir meraka tidak perlu lagi melakukan pelaporan PPh Pasal 22. Sedangkan berdasarkan Peraturan Menteri Keuangan Nomor 243/PMK.03/2014 "bendahara wajib melaporkan PPh Pasal 22 yang dipungut dengan menyampaikan SPT Masa PPh Pasal 22 paling lama 14 (empat belas) hari setelah Masa Pajak berakhir". Jadi berdasarkan Peraturan Menteri Keuangan tersebut bendahara seharusnya tetap melakukan pelaporan $\mathrm{PPh}$ Pasal 22 walaupun telah membayar melalui aplikasi e-billing.

\section{KESIMPULAN DAN SARAN}

\subsection{Kesimpulan}

Berdasarkan hasil pembahasan dari bab sebelumnya, maka dapat disimpulkan sebagai berikut :

1. Penerapan PPN dan PPh Pasal 22 atas Pengadaan Barang Pada Kantor Badan Pengawasan Keuangan dan Pembangunan Perwakilan Sulawesi dalam hal perhitungan dan penyetoran sudah mengikut undang-undang yang berlaku, namun ketika melakukan perhitungan Pajak Pertambahan Nilai dan Pajak Penghasilan Pasal 22 yang dilakukan oleh bendahara BPKP masih ada beberapa hasil perhitungan yang kurang tepat, sedangkan untuk penyetoran Pajak Pertambahan Nilai dan Pajak Penghasilan Pasal 22 bendahara BPKP melakukan penyetoran melalui aplikasi e-billing di mana bendahara membayar PPN dan PPh Pasal 22 dengan menggunakan kode billing melalui Bank BNI.

2. Dalam hal pelaporan Kantor Badan Pengawasan Keuangan dan Pembangunan Perwakilan Sulawesi Utara tidak melakukan pelaporan atas Pajak Pertambahan Nilai dan Pajak Penghasilan Pasal 22, karena menurut bendahara BPKP Perwakilan Sulawesi Utara setalah menggunakan aplikasi e-billing bendahara menganggap tidak perlu lagi untuk melakukan pelaporan atas Pajak Pertambahan Nilai dan Pajak Penghasilan Pasal 22, sedangkan berdasarkan PMK No. 243/PMK.03/2014 walaupun bendahara sudah melakukan penyetoran PPN dan PPh Pasal 22 melalui e-billing bendahara tetap harus melaporkan SPT Masa PPN dan SPT Masa PPh Pasal 22 kepada Direktorat Jenderal Pajak.

\subsection{Saran}

Adapun peneliti ingin memberikan saran yang dapat dijadikan bahan pertimbangan bagi Kantor BPKP Perwakilan Sulawesi Utara, antara lain:

1. Sebaiknya dalam melakukan perhitungan dan pembulatan lebih diperhatikan lagi, karena hal ini akan berakibat fatal jika transaksi terjadi dalam jumlah banyak, sehingga akan menimbulkan selisih yang signifikan.

2. Kantor BPKP Perwakilan Sulawesi Utara hendaknya melakukan arsip dokumen dengan baik. Hal ini akan mempermudah Kantor BPKP Perwakilan Sulawesi Utara jika suatu saat dokumen tersebut diperlukan untuk kebutuhan pemeriksaan.

3. Sebaiknya Kantor BPKP Perwakilan Sulawesi Utara melakukan pelaporan pajak sesuai dengan PMK No. 243/PMK.03/2014 agar di kemudian hari tidak dikenakan sanksi atas administrasi perpajakan. 


\section{DAFTAR PUSTAKA}

Darmayanti, Novi. 2012. Analisis Perhitungan Pajak Pertambahan Nilai Pada CV. Sarana Teknik Kontrol. Jurnal. Universitas Islam Darul Ulum Lamongan. Surabaya.

Kuncoro, M. 2013. Metode Riset Untuk Ekonomi dan Bisnis - Bagaimana Meneliti dan Menulis Tesis? Edisi Keempat. Penerbit Erlangga. Jakarta.

Lubis, Irsan. 2015. Mahir Akuntansi Pajak Terapan Berbasis Standar Akuntansi \& Ketentuan Pajak Terbaru. Penerbit Andi. Yogyakarta.

Mardiasmo. 2018. Perpajakan Edisi Terbaru 2018. Penerbit Andi. Yogyakarta.

Peraturan Menteri Keuangan Nomor 210/PMK.03/2008, Tentang Penunjukan Pemungut PPh Pasal 22, Sifat dan Besarnya Pungutan Serta Tata Cara Penyetoran dan Pelaporannya. Berita Negara Republik Indonesia Tahun 2008. Jakarta.

Peraturan Menteri Keuangan Nomor 154/PMK.03/2010, Tentang Pemungutan PPh Pasal 22. Berita Negara Republik Indonesia Tahun 2010 Nomor 427. Jakarta.

Peraturan Menteri Keuangan Nomor 243/PMK.03/2014, Tentang Surat Pemberitahuan (SPT). Berita Negara Republik Indonesia Tahun 2014 Nomor 1974. Jakarta.

Resmi, Siti. 2014. Perpajakan Teori dan Kasus Edisi 8 Buku 1. Penerbit Salemba Empat. Jakarta.

Soeradi, H. 2015. Bendaharawan Pemerintah: Optimalisasi Tugas dan Peranannya Sebagai Pemotong/Pemungut Pajak. Penerbit Graha Ilmu. Yogyakarta.

Surat Edaran Nomor SE-11/PJ/2016, Tentang Panduan Teknis Penerapan Sistem Pembayaran Pajak Secara Elektronik. Direktorat Jenderal Pajak Tahun 2016. Jakarta.

Undang-Undang Nomor 36 Tahun 2008 tentang Perubahan Keempat atas Undang-Undang Nomor 7 Tahun 1983 tentang Pajak Penghasilan.

Undang-Undang Nomor 42 Tahun 2009 tentang Perubahan Ketiga atas Undang-Undang Nomor 8 Tahun 1983 tentang Pajak Pertambahan Nilai Barang dan Jasa dan Pajak Penjualan atas Barang Mewah. 